\title{
Clinico-Pathological Presentation of Colorectal Cancer Seen in Lagos State University Teaching Hospital
}

\author{
Abiodun Popoola ${ }^{1}$, Nasiru Ibrahim² ${ }^{2}$ Folusho Omodele ${ }^{2}$, Ihuoma Igwilo $^{3}$, Sunday Soyemi ${ }^{4}$ \\ ${ }^{1}$ Lagos State University, College of Medicine, Department of Surgery, Radiology, Ikeja, Lagos, Nigeria; ${ }^{2}$ Lagos State College of University of \\ Medicine, Surgery, Ikeja, Lagos, Nigeria; ${ }^{3}$ Lagos State College of University of Medicine, Radiology \& Oncology Unit, Ikeja, Lagos, Nigeria; \\ ${ }^{4}$ Lagos State University, Pathology and Forensic Medicine, Ikeja, Lagos, Nigeria
}

\author{
Citation: Popoola A, Ibrahim N, Omodele F, \\ Igwilo I, Soyemi S. Clinico-Pathological \\ Presentation of Colorectal Cancer Seen in Lagos \\ State University Teaching Hospital. Maced J Med \\ Sci. 2012 Dec 15; 5(4):411-415. http://dx.doi.org/ \\ Sci. 2012 Dec 15; 5(4):411-415. http://dx.doi.org/
10.3889/MJMS.1857-5773.2012.0245. \\ Key words: colorectal cancer; age; \\ adenocarcinoma; gender; type; Nigeria. \\ Correspondence: Dr. Abiodun Popoola. Lagos \\ State University, College of Medicine, Department \\ of Surgery, Radiology, Ikeja, Lagos, Nigeria. E- \\ mail: pabiodun2001@yahoo.com \\ Received: 16-Mar-2012; Revised: 29-May-2012; \\ Accepted: 30-May-2012; Online first: 10-Oct-2012 \\ Copyright: (c) 2012 Popoola A. This is an open- \\ access article distributed under the terms of the \\ Creative Commons Attribution License, which \\ permits unrestricted use, distribution, and \\ reproduction in any medium, provided the origina \\ author and source are credited. \\ Competing Interests: The author have declared \\ that no competing interests exist.
}

\section{Abstract}

Aim: The objective is to describe the age and gender distribution, pattern of presentation, sites of colorectal cancers and the histological types of colorectal cancers seen over a 5 year period in a tertiary health institution (Lagos State University Teaching Hospital, Nigeria).

Design: A collected data of 104 patients with colorectal cancer from 2006 to 2011 formed the basis of this study.

Results: Sixty-five were males and thirty-nine female out of 104 colorectal cases. Age range was between 19 and 78 years. The male female ratio was 1.3:1. 28.8\% (30) of the patients presented with stage IV, 46.1 (48) presented with stage III, and 24\% (25) presented with stage II. The commonest histological type was adenocarcinoma (84.2\%), 46.4\% of which were well differentiated. $14.3 \%$ had no grade stated. The most common clinical features were suggestive of intestinal obstruction (vomiting \& abdominal pain).

Conclusion: Most patients in our study presented with late stage disease and this trend especially in this part of the world frequently result in high morbidity and mortality. Policies that promote Public Health education, screening programme which will lead to early diagnosis affordable and effective treatment should be considered.

\section{Introduction}

Colorectal Cancer is an important disease with a large morbidity and mortality rate worldwide $[1,2]$. The etiology of colorectal cancer appears to be multifactorial in role especially diet with high fat content[3] . Change in diet and lifestyle contributes to risk of developing colorectal cancer as described in a study by Elias Degiannis et al, where he found that there was an increased incidence of polyps proven histologically in association with colorectal carcinoma in affluent people (14\%) who have acquired westernized lifestyle as compared with people with poor rural lifestyle (5.5\%) [4].

The relative infrequency in Black Africa may be attributed to the young age of the population; shorter transit time of faeces, high fibre diet and rarity of precancerous conditions such as Familial Adenomatosis 
polyposis, ulcerative colitis and Crohns disease [5].

Globally, colorectal cancer is the third commonest malignant neoplasm after cancer of the lung and stomach in the male and after cancer of the breast and cervix in the female. It accounts for $8.8 \%$ of cancers in males and $9.2 \%$ in females [5]. It is the second most frequent cause of death in the Western Europe and America [1]. In Africa, this disease was considered rare but this is no longer true [2].

About $50 \%$ of large bowel malignancy occurs in the rectum, $25 \%$ in the pelvic colon, $12 \%$ in the ascending colon \& caecum, $10 \%$ in the transverse colon including the flexures and $3 \%$ in the descending colon [4]. Macroscopically, there are four pathological types of colorectal carcinoma, which includes the proliferative/ cauliflower which is predominant in the right/ascending colon; Malignant ulcer which is predominant in the rectum and retro sigmoid; Annular type predominant in the descending colon and notorious for evoking obstruction; and the Tubular/infiltrative type [5]. Microscopically, over $80 \%$ are adenocarcinoma, the rest being colloid or anaplastic carcinoma [5].About 5\% of the people with colon or rectal cancer have more than one pathological type at the same time [6].

According to a bibliography collated in the United Kingdom, a one-time flexible sigmoidoscopy screening between 55 and 64years of age reduced colorectal cancer incidence by $33 \%$ and mortality by $43 \%$ [7]. It was found that the 5 year survival rates of cancer in the intestinal lining (mucosae) only was $90 \%$; penetrating muscle layer of the intestine $80 \%$ and cancer spread to lymph nodes 30\% [6].

Despite intensive investigations over the past decade, there has been no improvement in the long term prognosis of most patients with advanced disease. These patients have an estimated five year survival rate of $5 \%$ (excluding the comparatively small number of patients who have disease limited to the liver, which is suitable for surgical resection or ablative techniques) [8]. Chemotherapy is effective in prolonging the time to disease progression and survival in patients with advanced colorectal cancer [8]. The primary treatment is surgical resection, but over half of all patients will eventually die of metastatic disease. Although the rate of progression of advanced colorectal cancer is variable, patients have a median survival of only 6-9 months from the diagnosis of metastatic disease [8].

\section{Material and Methods}

\section{AIM \& OBJECTIVES}

To describe the age at presentation and gender distribution, pattern of presentation, sites of colorectal cancers and the histological types of colorectal cancers seen over a 5 year period in a tertiary health institution (Lagos State University Teaching Hospital, Nigeria) with the aim of improving the awareness of the disease, furthering research into more effective \& affordable therapy, galvanizing the establishment of support programs where enlightenment campaigns to improve awareness, free screening exercise, therapeutic \& Psychological counseling of patients could be carried out and possible Government-subsidised drugs , can be made accessible to the target population.

\section{Materials}

A total of 104 patients with histological confirmed cases of colorectal cancer form the basis of this study from 2006 to 2011. The patients were referred from the surgical to the oncology unit of the Lagos State University Teaching Hospital. These patients were followed up for a period of 5 years. The records of the patients which contain their background characteristics such as age, sex, clinical, radiologic and pathological variables including histological type, grade and stage were analysed.

Pretreatment investigation includes Full blood count, chest X-ray, barium enema and CT-scan of the abdomen (which is not routinely done).

\section{Limitations}

Histopathological grading was not included in the analysis of 13 patients' report. Also, of 110 patient files collated, 6 (six) had missing data such that only the age of the patient could be obtained and thus recorded (as seen in Table 1). The remaining cases (104) which contained more useful information were used in the analysis of this work.

\section{Results}

Sixty-five were males and thirty-nine female out of 104 colorectal cases. Age range is between 19 and78 years. The male female ratio is 1.3:1. The median age was 55 years and the peak age was the $6^{\text {th }}$ decade of life as shown in Table 1 . The major clinical features were change in bowel habits, constipation, features of 
Popoola et al. Clinico-Pathological Presentation of Colorectal Cancer Seen in Lagos State University Teaching Hospital

Table 1: Age Distribution of Colorectal cancer.

\begin{tabular}{ccc}
\hline Age & Number $(\mathrm{N})$ of patients & $\%$ of Total \\
\hline $15-25$ & 3 & 2.7 \\
$26-35$ & 13 & 11.8 \\
$36-45$ & 16 & 14.5 \\
$46-55$ & 27 & 24.5 \\
$56-65$ & 34 & 30.9 \\
$>65$ & 17 & 15.4 \\
\hline Total & 110 & 100 \\
\hline
\end{tabular}

obstruction-vomiting, abdominal swelling/pain and constipation; rectal bleeding, weight loss and some cases were found during routine checkup.

Table 2: Distribution of the various histological types.

\begin{tabular}{lcc}
\hline Histological Type & N of patients & $\%$ of Total \\
\hline Adenocarcinoma & 88 & 84.62 \\
Mucinous & 5 & 4.81 \\
Fibro sarcoma & 1 & 0.96 \\
Others (Pleomorphic carcinoma, Malignant & 10 & 9.62 \\
lymphoma) & 104 & 100 \\
Total & \\
\hline
\end{tabular}

Majority presented with left sided tumour (descending colon/sigmoid/rectal) 53.8\% (57). Right sided tumour (caecum, ascending colon) $41.5 \%$ (44) and transverse colon $2.8 \%$ (1).

Table 3: Distribution of the various histological grades of Adenocarcinoma (refer to Table 2 above). Other histological types were not graded.

\begin{tabular}{lcc}
\hline Grade & $\begin{array}{c}\text { Number of } \\
\text { Patients }\end{array}$ & Percentage (\%) \\
\hline Well differentiated & 40 & 46.4 \\
Moderately & 29 & 32.1 \\
differentiated & 6 & 7.1 \\
Poorly differentiated & 13 & 14.3 \\
Not Stated & \\
\hline
\end{tabular}

$28.8 \%(30)$ of the patients presented with stage IV, 46.1(48) presented with stage III, and 24\% (25) presented with stage II as shown in Table 4.

Eighty-four point two percent (84.2\%) of the colorectal cases were adenocarcinoma, of which $46.4 \%$ were well differentiated, $32.1 \%$ moderately differentiated

Table 4: Distribution of the various stages of the disease.

\begin{tabular}{lcc}
\hline Stage of disease & Number of patients & \% of Total \\
\hline I & 1 & 0.96 \\
II & 25 & 24 \\
III & 48 & 46.1 \\
IV & 30 & 28.8 \\
Total & 104 & 100 \\
\hline
\end{tabular}

Maced J Med Sci. 2012 Dec 15; 5(4):411-415.
Table 5: Sub site distribution of colorectal cancer.

\begin{tabular}{lcc}
\hline Symptoms & $\begin{array}{c}\text { Number of } \\
\text { patients }\end{array}$ & \% of Total \\
\hline Caecum & 9 & 8.5 \\
Ascending & 35 & 33 \\
Transverse & 3 & 2.8 \\
Sigmoid & 14 & 13.2 \\
Rectum & 43 & 40.6 \\
Total & 104 & 100 \\
\hline
\end{tabular}

and $71 \%$ were poorly differentiated. However, in $14.3 \%$, the histological grade was not stated. Other histological types were not graded as shown in Tables 2 \& 3 .

Table 6: Distribution of Clinical features at presentation of colorectal cancer.

\begin{tabular}{lcc}
\hline Symptoms & Number of patients & \% of Total \\
\hline Abdominal pain & 27 & 27.9 \\
Vomiting & 18 & 17.3 \\
Abdominal Distension & 13 & 12.5 \\
Bleeding & 17 & 16.3 \\
Combination of 2 or 3 above symptoms & 11 & 10.6 \\
Incidental finding & 18 & 17.3 \\
\hline
\end{tabular}

In addition, of the histological types, $4.81 \%$ were mucinous, 0.96\% were fibro sarcoma and 9.62\% (10) represented the 'others' (pleomorphic carcinoma and malignant lymphoma) (refer to the response to the reviewer comment below).

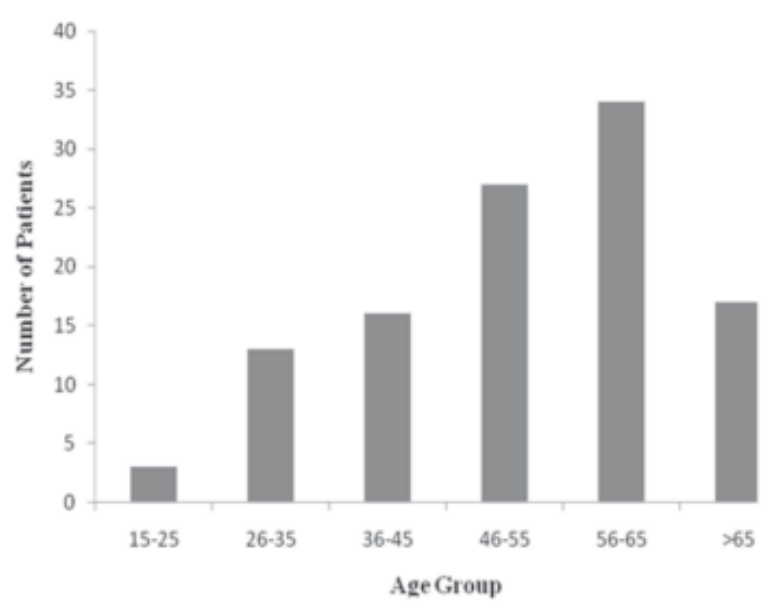

Figure 1: Bar chart showing the Age distribution of patients. 


\section{Discussion}

The epidemiological pattern of the disease varies markedly between different populations group [9] Colorectal cancer is the third most common malignancy in both men and women worldwide [1] and the second most frequent cause of death in the Western Europe and America [1]. In Africa, this disease was considered to be rare but this is no longer true [2]. However, the molecular pathophysiology remains similar throughout the world [10].

The incidence of colorectal cancer begins to rise at age 40 and peaks between ages 60 and 75 years

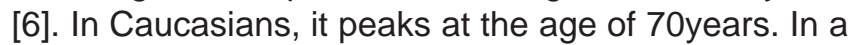
study, $57 \%$ were over 70 years while an incidence of $4 \%$ was found among young people [11]. In Africa on the average, patients were $10-15$ years younger and onethird were 40 years and below [2, 12]. In our study, $62 \%$ of the patients were 40years and above; the peak age is between 56-65 years and male female ratio of 1.3:1. The Youngest patient was 19 years old while the oldest patient was 78 years old.

Majority of patients presented with features of obstruction (vomiting, abdominal pain and abdominal distention), altered bowel habit and evidence of lower gastrointestinal bleeding.

Most of our patients presented late with advanced disease as shown by the TNM staging ,thus, corroborating a retrospective study done in Maiduguri, Nigeria where mortality and morbidity remain high because of late presentation which may be due to the fact that colorectal cancer has a biologically more aggressive course in Africa and this contribute to the unfavorable staging at the time of presentation and this is further worsened by the combination of ignorance and high cost of medical care [10]. Blacks are more likely to present at a younger age with right sided tumours which are frequently advanced at presentation, as compared with the left sided tumours. They are also likely to present with increased proportions of lower grade tumours which may grow more slowly and be less likely to respond to treatment which lead to lower response rate in blacks, hence, poorer outcome [15].

Sub site distribution in our study recorded that majority of patients present with cancer of rectum or sigmoid colon , $40.6 \%$ and $13.2 \%$ respectively which is comparable to a study carried out by Mohammed et al, E.A.Badoe et al. and studies in the United Kingdom $[5,13,14]$. Caecum and ascending colon presented with $8.5 \%$ and $33 \%$ respectively while

\section{transverse colon presents with $2.8 \%$}

The histopathological variety of majority of the patients is adenocarcinoma(84.62\%) with $46.4 \%$ of it being well differentiated, $32.1 \%$ moderately differentiated and $7.1 \%$ poorly differentiated. $4.8 \%$ of the adenocarcinoma are mucinous. Other histopathological varieties are fibro sarcoma $(0.96 \%)$, pleomorphic carcinoma and malignant lymphoma $(9.62 \%)$. It is noteworthy to indicate at this point that the histopathological grade for $13(14.3 \%)$ cases were not stated and 18 (19.4\%) patients were incidental findings. This pattern is similar to the study carried out by Yawe et al in Maiduguri, Nigeria [10].

In Lagos State University Teaching Hospital, as soon as the patients have been diagnosed histopathologically, they are referred from the surgical unit to the Oncology Centre with a documentation of the histology report. A work up (Full blood count, Chest Xray and Abdominal ultrasound scan) is done on these patients to detect possible metastasis and to have a baseline haematological picture. A treatment plan is discussed with the patient and their care givers; in view of their state of health, presence of metastasis and affordability of the drugs, they are then placed on a treatment regime. The various regimes incorporated in our clinic includes; FOFLOX (5-FU, Leucovorin \& Oxaliplatin); XELOX (Capecitabine \& Oxaliplatin); FOLFIRI (5-FU, Leucovorin \& Irinotecan); For patients who cannot afford the regimes mentioned are placed on I.V. 5 -FU $500 \mathrm{mg} / \mathrm{m} 2$ daily for 5 days, rest for 28 days, then weekly for 52 weeks combined with Tab Levamisole $50 \mathrm{mg}$ thrice daily 2 days a week, alternate weeks. There are no support programs promoting awareness and screening of Colorectal Cancer by the tertiary institution or the government. However, the latter supports indigent colorectal cancer patients who cannot afford their treatment.

Even though Adenocarcinoma was one of the commonest histopathological type mentioned, malignant lymphoma and fibro sarcoma, which are also histological types of colorectal carcinoma, were relegated as 'others' because these were suspected, not confirmed and the number of cases were too few to be analysed under this study.

Conclusion: Most patients in our study presented with late stage disease, accompanied by symptoms of obstruction and well differentiated Adenocarcinoma type. The incidence of advanced/late presentation of Colorectal Cancer in Africa result in high morbidity and mortality. 
Policies that will promote Public Health education, screening programme which will lead to early diagnosis thus better prognosis, affordable and effective treatment should be implemented.

\section{References}

1. Naader SB, Archampong EQ. Cancer of the colon and rectum in Ghana:A five year prospective study of Ghana Medical School, Accra. BJ of Surg. 1994;81:456-459.

2. Adesanya AA, Darocha-Afodu JT. Colorectal Cancer in Lagos; A critical review of 100 cases. The Nig Postgraduate Med Journal. 2000;7(3).

3. James AM, Leonard LG. Colon and Rectum;Principle and Practice of Radiation Oncology; $3^{\text {rd }}$ ed. Lippincott-Raven Publisher, 1997:1489-1506.

4. Elias D, Karan S, Richard L, Martin JH, Roger S. Tropical Gastroenterology Journal; Clinopathological trends in Colorectal Carcinoma in a Black South African Population. 1995;16(4):6.

5. Badoe EA et al, ed.; Malignant tumours of the colon and rectum. In: Badoe EA et al., eds. Principles and Practice of Surgery, $3^{\text {rd }}$ edition, 670.

6. Berkow R, ed. The Merck manual of Medical Information, Home Edition. Colorectal cancer, 1997:553-554.

7. Ahmedin Jemal DVM et al. Global Cancer Statistics. Cancer Journal. 2011;61(2):69-90.
8. Allumv WH et al. Cancer of the colon and rectum in the West Midlands 1957-1981. British Journal of Surgery. 1994;81:1060-1063.

9. Schottenfeld $D$, ed. The epidemiology of cancer: an overview. 1981;47:1095-108.

10. Yawe KT, Bakari AA, Pindiga UH, Mayun AA. Clinicopathological pattern and challenges in the management of colorectal cancer in Sub-saharan Africa. Journal of Chinese Clinical Medicine. 2007;2(12):688.

11. Ameh A, Paul T, NMADN, Abdulmumini, Rafin Dadi et al. Colorectal and Anal Cancer in Zaire. Overseas pubisher Association, N.V by the Harwood Academic Publisher in Malaysia. GIT Cancer. 1999;3(1):11-15.

12. Simmonds P. Chemotherapy for Advanced Colorectal Cancer. British Medical Journal. 2000;321:521-2.

13. Mohammed IA, Assem OA, Adel MK, Abdul HN, Iqbal AM. Clinicopathological trends in colorectal cancer in a tertiary care hospital. Saudi Med J. 2000;23(2):163.

14. Isbister WH. Sex and Subsite frequency of large bowel cancer in Kingdom of Saudi Arabia. A comparison with New Zealand. Aust N Z J Surg. 1992;62:350-353.

15. Hanna KS, Daniel JS, Erin MG, et al. Racial Differences in Advanced Colorectal Cancer Outcomes and Pharmacogenetics: A Subgroup Analysis of a Large Randomized Clinical Trial. Journal of Clinical Oncology. 2009;27(25):4109-4115. 